\title{
Revista
}

Uberaba, v. 4, n. 1, p. 01-12, jul./dez. 2011. ISSN: 2175-1609

\section{ALFABETIZAÇÃo CIENTÍFICA EM NÍVEL MÉDIO E A PREPARAÇÃo DOS CIDADÃOS PARA O PROCESSO DE TOMADA DE DECISÕES ${ }^{1}$}

\section{SCIENTIFIC LITERACY IN SECONDARY SCHOOLS AND THE PREPARATION OF CITIZENS FOR THE DECISION-MAKING PROCESS}

Danilo Rothberg ${ }^{2}$, Gabriel Augusto Cação Quinato ${ }^{3}$

\footnotetext{
${ }^{1}$ Uma versão inicial deste texto foi apresentada no IV Simpósio Nacional de Tecnologia e Sociedade, realizado na Universidade Tecnológica Federal do Paraná (UTFPR), de 9 a 11 de novembro de 2011.

${ }^{2}$ Doutor em Sociologia pela Universidade Estadual Paulista Júlio de Mesquita Filho. Docente da Unesp Universidade Estadual Paulista, Faculdade de Arquitetura, Artes e Comunicação, Departamento de Ciências Humanas.

${ }^{3}$ Mestrando do Programa de Pós-Graduação em Educação para Ciência da Faculdade de Ciências da Unesp Universidade Estadual Paulista
} 


\section{Revista}

\title{
RESUMO
}

O conceito de alfabetização científica encontra-se na atualidade permeado por princípios eventualmente incompatíveis entre si. Desenvolvimento de habilidades cognitivas, preparação para a continuidade dos estudos em nível superior, ingresso no mercado de trabalho e formação da cidadania estão entre os objetivos da educação para a ciência, que muitas vezes competem entre si no cotidiano escolar. No contexto das relações CTSA (Ciência, Tecnologia, Sociedade e Ambiente), a dimensão política da ciência deve ser contemplada pelo ensino de ciências. Este artigo revisa o conceito de alfabetização científica no contexto das relações CTSA e caracteriza razões e meios para que o ensino de física em nível médio contemple os conteúdos curriculares sobre consumo e produção de energia, a fim de prover a formação necessária para avaliar políticas públicas de ciência, tecnologia e inovação, em particular o Plano Decenal de Expansão de Energia 2020, posto em consulta pública pelo Ministério de Minas e Energia em 2011.

Palavras-chave: Ensino de Física. Relações CTSA. Alfabetização científica.

\begin{abstract}
The concept of scientific literacy nowadays is permeated by principles eventually inconsistent. Development of cognitive skills, preparation for continuing studies in higher education, preparation for working life and the strengthening of citizenship are some of the competing goals of science education. In respect of Science, Technology, Society and Environment (STSE) Education, the politics of science should be properly taken into account by science education. This paper examines the concept of scientific literacy in the context of STSE Education and points to why and how physics education in high school curriculum should address topics of energy consumption and production in order to provide the background necessary to assess public policies of science, technology and innovation, in particular the Decennial Plan for Expansion of Energy 2020, subjected to public consultation by the Brazilian Ministry of Mines and Energy in 2011.
\end{abstract}

Keywords: Teaching of Physics. Relations STSR. Scientific literacy 


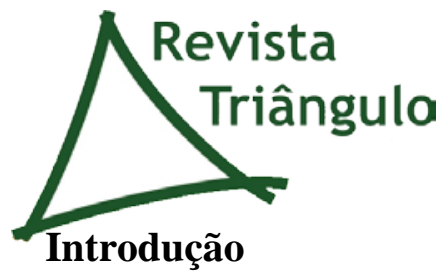

Uberaba, v. 4, n. 1, p. 01-12, jul./dez. 2011. ISSN: 2175-1609

No atual cenário socioeconômico global, a presença da ciência e da tecnologia (C\&T) é marcante: a maioria dos instrumentos que usamos, assim como as atitudes e os comportamentos que adotamos, são permeados por C\&T, de maneira que as democracias contemporâneas passaram a criar, gradativamente, espaços, oportunidades e procedimentos para que as pessoas possam influenciar nas decisões que geram impacto sobre seu uso cotidiano.

Atualmente, considera-se que as interações entre os processos de avanço do conhecimento e a sociedade devem repercutir sobre a formação da cidadania. Dar condições para que o cidadão possa interagir ativamente com a sociedade na esfera das decisões sobre as aplicações de ciência e tecnologia tem se mostrado um objetivo importante a ser alcançado no mundo contemporâneo. Um dos objetivos da alfabetização científica é preparar os cidadãos para a participação nos processos de tomada de decisões na esfera política, evitando que a responsabilidade sobre o desenvolvimento técnico-científico recaia única e exclusivamente sobre uma pequena elite científica e política supostamente qualificada.

Em determinadas áreas do ensino, o incentivo à interação social para a avaliação de políticas públicas pode se associar a conteúdos curriculares específicos. Este artigo revisa o conceito de alfabetização científica no contexto das relações CTSA (Ciência, Tecnologia, Sociedade e Ambiente) e caracteriza razões e meios para que o ensino de física em nível médio contemple conteúdos curriculares sobre consumo e produção de energia, a fim de prover a formação necessária para avaliar políticas públicas de ciência, tecnologia e inovação, em particular o Plano Decenal de Expansão de Energia 2020, posto em consulta pública pelo Ministério de Minas e Energia em junho de 2011 e aprovado pela Portaria no . 689, de 28 de dezembro de 2011.

\section{Alfabetização científica e CTSA}

A alfabetização científico-tecnológica é buscada mais comumente no âmbito escolar, mas esse não é o único espaço onde ela pode ocorrer, já que também pode ser um objetivo de espaços educativos informais e de divulgação científica (KRASILCHIK, 2009; TEDESCO, 2009; SOUZA, BASTOS e ANGOTTI, 2007; ACEVEDO, 2004; FONTES e SILVA, 2004). Nessa perspectiva, consideramos como relevante para o âmbito escolar a adoção de um 


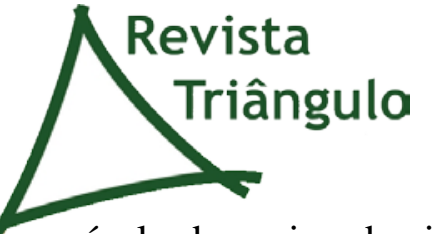

Uberaba, v. 4, n. 1, p. 01-12, jul./dez. 2011. ISSN: 2175-1609

currículo de ensino de ciências com ênfase no enfoque Ciência-Tecnologia-Sociedade (CTS), ou ainda Ciência-Tecnologia-Sociedade-Ambiente (CTSA), que procura preparar o aluno para o exercício da cidadania e caracteriza-se por uma abordagem dos conteúdos científicos em seu contexto social, além de indicar que a melhoria da qualidade educacional implica uma apropriação do conteúdo abordado, de forma que os alunos sejam capazes de, de posse desses conhecimentos, realizar uma leitura crítica da realidade, conforme indica Auler (2003, p. 72), para quem a educação em ciências deve "propiciar a compreensão do entorno da atividade científico-tecnológica, potencializando a participação de mais segmentos da sociedade civil” em duas direções: na "avaliação dos impactos pós-produção definição de parâmetros em relação ao desenvolvimento científico-tecnológico” e “na definição da agenda de investigação”.

No entanto, vários trabalhos alertam para a existência de diversas dificuldades e obstáculos na busca por essa natureza de alfabetização científica (ACEVEDO, 2004, 2006, 2008; PRAIA, GIL-PÉREZ E VILCHES, 2007; SANTOS, 2007; AULER, 2003; AULER e DELIZOICOV, 2001).

Entre os obstáculos listados pela literatura especializada, discutiremos aqui os que consideramos mais significativos para o contexto em questão. Auler e Delizoicov (2001) apontam a existência de mitos relacionados às interações CTSA que se caracterizariam como construções que surgem paralelamente ao desenvolvimento do conhecimento científico e tecnológico e acabam desencadeando a aceitação de ideias que nem sempre condizem com a atividade científico-tecnológica. Entre eles podemos citar a crença na superioridade do modelo de decisões tecnocráticas, que tende a considerar a ciência e a tecnologia como superiores, neutras e incorruptíveis, que teriam como único objetivo o desenvolvimento pleno e a busca pelo progresso. Nessa imagem, são desconsiderados fatores importantes, tais como o cenário sociopolítico em que as decisões são tomadas e as políticas de C\&T são desenvolvidas.

Outro mito relacionado às interações CTSA é a perspectiva salvacionista, segundo a qual todos os problemas sociais existentes seriam resolvidos automaticamente pelo avanço da ciência e tecnologia. Se em dado momento não existirem C\&T capazes de resolvê-los, em algum momento elas serão desenvolvidas para tal, novamente ignorando a não neutralidade das políticas e a necessária participação social na busca de soluções. O modelo de tomada de 
Revista Triângula

Uberaba, v. 4, n. 1, p. 01-12, jul./dez. 2011. ISSN: 2175-1609

decisões tecnocientíficas sob a perspectiva salvacionista da C\&T culmina em um determinismo tecnológico que posiciona a tecnologia como vetor central de mudanças sociais, desconsiderando-se fatores como as demandas específicas do desenvolvimento humano e as injunções do cenário sócio-econômico-político.

Se as críticas a esses mitos advêm dos estudos das relações CTSA, a sociedade como um todo progressivamente começa a dar sinais de reconhecimento acerca desses problemas, principalmente no que diz respeito à relevância de trazer cada vez mais as relações entre C\&T para o debate político, atentando principalmente para os possíveis problemas em relação à sustentabilidade (LÚJAN et al, 1996).

No âmbito escolar, a abordagem dos conteúdos curriculares sob o enfoque CTSA tem merecido estudos específicos, na busca de contemplar objetivos nem sempre compatíveis entre si. Praia, Gil-Pérez e Vilches (2007) apontam as complicações geradas pelo elevado número de conhecimentos que teriam que ser incluídos na educação básica na busca por alfabetização científica, concomitantemente à complexidade relacionada aos novos conhecimentos científicos. Uma dificuldade é conciliar a necessidade de educação científica cidadã para a maioria dos educandos com a exigência de uma educação científica mais específica para aqueles que pretendam seguir seus estudos em nível técnico e superior.

Outro desafio é evitar a reprodução de imagens distorcidas acerca do que vem a ser a atividade científica, presentes por exemplo, na ideia do método científico como processo fechado, cercado por orientações fixas e imutáveis; na imagem do cientista que trabalha sozinho em seu laboratório e se mantém distante da sociedade; e na idealização da ciência como criação a partir de dados puros e livre de erros ou influências externas (ACEVEDO, 2008; PRAIA, GIL-PÉREZ E VILCHES, 2007; FONTES E SILVA, 2004).

Também deve ser superada a incongruência muitas vezes existente entre o currículo adotado pela instituição de ensino, os agentes sociais envolvidos como professores, as políticas educacionais, os próprios alunos e as avaliações aplicadas, o que acaba culminando em um decréscimo na qualidade do ensino, já que os objetivos de cada uma das esferas participantes podem não conversar entre si, impossibilitando seu pleno desenvolvimento (SANTOS, 2007). 


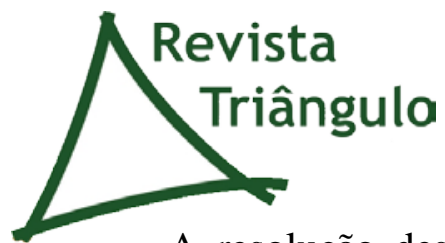

Uberaba, v. 4, n. 1, p. 01-12, jul./dez. 2011. ISSN: 2175-1609

A resolução dessas insuficiências deve resultar na ampliação das oportunidades de busca por uma alfabetização científica mais abrangente, por meio de, por exemplo, criação de práticas pedagógicas que associem conteúdos curriculares atualmente presentes no ensino de ciências às dinâmicas dos processos sociais de formulação de políticas de ciência e tecnologia (BRASIL, 1996, 2006; SANTOS e MORTIMER, 2000).

Nesse sentido, sugerimos a relevância de lidar, em sala de aula, com assuntos que, por sua própria novidade e subordinação a processos políticos de regulação em curso, ainda esperam por ser tratados mais adequadamente na esfera escolar, como, por exemplo, descarte de materiais radioativos, formas mais limpas de obtenção de energia, uso de novos materiais sobre os quais ainda não existe consenso acerca da sua nocividade à saúde humana, biotecnologia, desenvolvimento de novos medicamentos, pesquisa com células tronco etc. Nessa linha de confronto com o que ainda não é definitivo, pode-se buscar a formação cidadã, já que, se na escola o aluno adquirir o hábito de investigar as implicações das novidades científicas e de interesse geral, posicionando-se criticamente frente ao que lhe é apresentado, nas interações sociais extraescolares terá mais chances de apresentar tal comportamento frente ao que lhe for apresentado enquanto cidadão participativo da sociedade em que está inserido.

Entre as diversas temáticas de C\&T presentes nos processos sociais de formulação de políticas públicas na atualidade, apontamos aqui um exemplo que pode trazer a oportunidade de desenvolvimento de abordagens pedagógicas apropriadas ao enfoque CTSA de um conteúdo atualmente contemplado pelo currículo escolar das escolas paulistas de nível médio. Trata-se do tópico de produção e consumo de energia elétrica, que está incluído nos Cadernos do Aluno (SÃO PAULO, 2010a) e do Professor (SÃO PAULO, 2010b) publicados pelo governo do Estado de São Paulo no ano de 2010, e que pode ser relacionado a uma dinâmica bastante atual dos processos de produção de políticas de ciência e tecnologia, consubstanciada no Plano Decenal de Expansão de Energia 2020 (BRASIL, 2011) posto em consulta pública através da Internet pelo Ministério de Minas e Energia em junho de 2011 e aprovado pela Portaria ${ }^{\circ}$. 689, de 28 de dezembro de 2011.

As consultas públicas on-line são meios de construção compartilhada de diretrizes de políticas públicas e legislações. Um setor governamental submete uma versão inicial do texto sob consulta pela Internet, e indivíduos e setores podem "se manifestar sobre cada aspecto proposto, indicar a necessidade de mudanças, justificar o porquê das sugestões, conhecer as 


\begin{abstract}
Revista Triângula

Uberaba, v. 4, n. 1, p. 01-12, jul./dez. 2011. ISSN: 2175-1609

contribuições de outros participantes, rever seus conceitos após descobrir as posições alheias etc.” (ROTHBERG, 2010, p. 2). Nesse sentido, sugerimos que os processos formais de ensino de ciências podem ser enriquecidos através de práticas pedagógicas que, em busca de meios para tornar mais atraentes as situações de aprendizagem, façam correlações com os mecanismos democráticos disponíveis atualmente para socializar a decisão em torno de políticas públicas de ciência e tecnologia.
\end{abstract}

\title{
O PDE 2020 sob a abordagem CTSA
}

O Plano Decenal de Expansão de Energia 2020 (PDE 2020) delineia uma previsão de como se comporta a expansão da demanda e da oferta de energia no Brasil no período compreendido entre 2011 e 2020 (BRASIL, 2011). Ele se distingue por ter sido submetido à consulta pública pela Internet entre 2 de junho e $1^{\circ}$ de julho de 2011.

O documento apresenta projeções de demanda em relação a vários aspectos. Entre os responsáveis pelo aumento da necessidade energética, estão o desenvolvimento socioeconômico do país, que acarreta maior número de domicílios com energia elétrica, com bens de consumo e eletrodomésticos, e o desenvolvimento industrial, com o aumento da frota de veículos automotores. O plano também propõe formas de atendimento do aumento esperado de demanda, como a inclusão de novas geradoras de energia no quadro nacional, como a usina hidrelétrica de Belo Monte e o potencial projetado para o gás natural encontrado na camada do pré-sal; além da possibilidade de compra de energia excedente de usinas hidrelétricas internacionais em fase de instalação; da melhoria da eficiência das geradoras já existentes, da melhoria da eficiência e do aumento das linhas de transmissão; da inclusão de fontes renováveis, como a queima do bagaço da cana-de-açúcar em usinas que produzem açúcar e etanol; da troca de equipamentos antigos por equipamentos mais novos e eficientes; e do aumento da tecnologia existente, o que consequentemente produzirá equipamentos mais econômicos. Novas formas de diminuição do consumo também são discutidas.

Cabe ressaltar alguns pontos do uso potencial do documento no ensino, tanto negativos como positivos.

Como aspecto positivo, sua utilização em sala de aula possibilitaria o tratamento de assuntos controversos e que estiveram presentes no cenário construído pelo jornalismo 


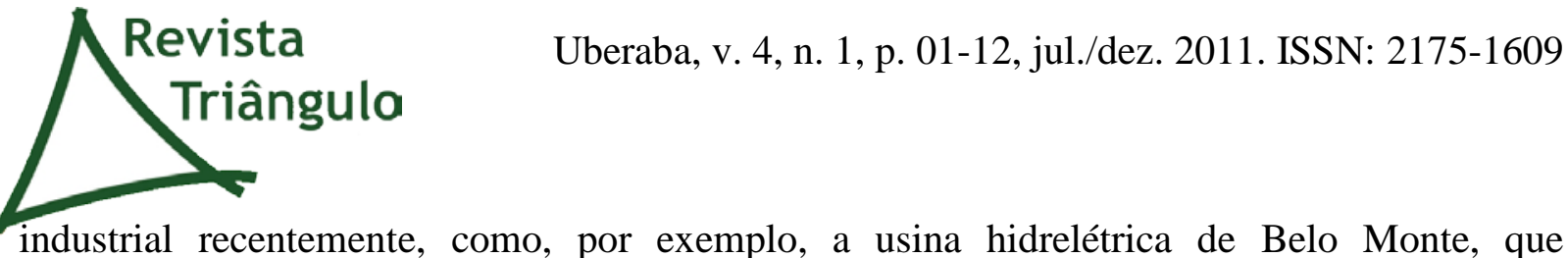
despertou controvérsia devido à área que deve ser alagada para sua instalação e ao consequente deslocamento populacional; à destinação dos resíduos nucleares produzidos pelas usinas Angra 1 e 2, sua segurança e a possível instalação de Angra 3; e ao potencial esperado do gás natural na exploração da camada do pré-sal. Também possibilitaria uma abordagem interdisciplinar sobre os conteúdos que apresenta, como o que implicaria para o Brasil a compra de energia elétrica excedente de outros países, assunto que pode ser discutido tanto no quesito das relações sociopolíticas e econômicas envolvidas quanto no potencial energético ocioso no território nacional e que deixa de ser aproveitado pelo Brasil, e a eficiência do gás natural com relação a outras fontes, como ele é formado, se é mais poluente que combustíveis renováveis.

Como aspecto negativo, há, no PDE 2020 (BRASIL, 2011), uma forte propagação da imagem salvacionista da ciência e tecnologia; o papel da sociedade como um todo no processo de economia e produção de energia é obscurecido pelos avanços tecnológicos, afastando assim a C\&T das suas relações com a sociedade.

De acordo com o currículo escolar do estado de São Paulo, no que diz respeito às ciências da natureza e suas tecnologias, os temas relacionados à eletricidade devem ser trabalhados na terceira série do ensino médio, no primeiro e segundo bimestres, sendo que o tema produção e consumo de energia elétrica é colocado como específico do segundo bimestre, como conteúdo curricular da grade de Física (SÃO PAULO, 2010c). Esse material didático, com frequência, parece buscar a aproximação entre o que é tratado dentro de sala de aula e o cotidiano dos alunos, com uma abordagem diferenciada, baseada em atividades a serem executadas dentro ou fora da sala de aula, o que não se esgota na mera transmissão de conceitos. Embora não seja possível, dentro das dimensões deste artigo, uma avaliação mais abrangente do mérito da abordagem, vale reter que, durante as atividades previstas, os alunos devem ter contato com conceitos básicos relacionados ao eletromagnetismo e a temas como o funcionamento de uma usina hidrelétrica, outras formas de produção de energia, redes de transmissão, motores e geradores elétricos, consumo residencial e formas de economia, evolução da produção e do uso de energia elétrica e sua relação com o desenvolvimento econômico e social, além de termodinâmica e bioenergia. Todos esses temas são referidos pelo PDE 2020 (BRASIL, 2011). 


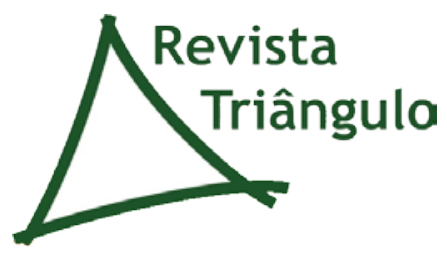

Uberaba, v. 4, n. 1, p. 01-12, jul./dez. 2011. ISSN: 2175-1609

Podemos sugerir que esses aspectos compõem um substrato adequado ao aprofundamento sob o enfoque CTSA, que avance no sentido de incluir temas atuais a fim de contribuir para o desenvolvimento de competências de leitura crítica da realidade contemporânea. Conteúdos relacionados ao funcionamento de uma usina hidrelétrica podem ser complementados com análises da eficiência de produção de energia por essa via e de sua distribuição, dos custos envolvidos na sua instalação e sua comparação com investimentos necessários às reformas das usinas já existentes para se chegar a um aumento na produção de energia equivalente ao que será produzido pela Usina Hidrelétrica de Belo Monte. As abordagens em sala de aula, em sintonia com as demandas por conhecimento trazidas pela consulta pública do PDE 2020, envolveriam também análises da possibilidade de que fontes mais limpas e menos impactantes possam ser desenvolvidas no país, como a solar, a eólica, a de biomassa e a de marés, e comparações entre a matriz energética nacional e a de países como EUA, Inglaterra, Alemanha, França e Japão nos aspectos de eficiência, grau de periculosidade, custo da produção e tecnologias envolvidas.

\section{Conclusões}

Sugerimos que, para praticar o enfoque CTSA no ensino de Física, em relação ao estudo de conceitos envolvidos na produção de energia, o docente deveria esclarecer como o domínio de conteúdos escolares se revela importante para a compreensão do processo social de formulação de decisões sobre políticas públicas de ciência e tecnologia.

Sustentamos que conteúdos curriculares hoje presentes no ensino médio podem servir a um tratamento atual de problemáticas sociais de grandes dimensões, como na oportunidade aqui indicada de associação produtiva entre tópicos de ensino sobre produção e consumo de energia e a oportunidade de participação no debate público sobre o Plano Decenal de Expansão de Energia 2020 (BRASIL, 2011), submetido à consulta pública pela Internet pelo Ministério de Minas e Energia entre 2 de junho e $1^{\circ}$ de julho de 2011, e aprovado pela Portaria $n^{\circ}$. 689, de 28 de dezembro de 2011.

As consultas públicas são uma inovação recente do processo político brasileiro, e nem sempre estão claros seus objetivos, público-alvo e resultados esperados (ROTHBERG, 2008). No entanto, elas indicam que o país, a exemplo da Europa e dos Estados Unidos, começa a 
reconhecer que as políticas públicas de diversas áreas, entre elas a ciência e a tecnologia, não podem prescindir da participação pública em sua formulação, se pretendem ser eficientes e eficazes. Se em muitos países a transparência e a participação na produção de políticas de C\&T obedecem a um requisito legal (IRWIN, 2008), no Brasil já se identifica uma tendência recente de realização de consultas públicas de políticas da área. A alfabetização científica não deveria ignorar esse quadro. Este texto ofereceu contribuições preliminares para indicar razões e meios pelos quais o ensino de ciências poderia assimilar suas implicações para a formação da cidadania.

\section{Agradecimentos}

Ao CNPq, pelo auxílio financeiro concedido no âmbito do Edital MCT CNPq MEC CAPES 022010.

\section{Referências}

ACEVEDO, J. A. D. Reflexiones Sobre las Finalidades de La Enseñanza de las Ciencias: Educación Científica para la Ciudadanía. Revista Eureka sobre Enseñanza y Divulgación de las Ciencias, vol. 1, $\mathrm{n}^{\mathrm{o}}$ 1, p. 3-16, 2004.

ACEVEDO, J. A. D. Modelos de Relaciones Entre Ciencia y Tecnología: Un Análisis Social e Histórico. Revista Eureka sobre Enseñanza y Divulgación de las Ciencias, vol.3, n² 2, p. 198-219, 2006.

ACEVEDO, J. A. D. El Estado Actual de la Naturaleza de La Ciencia en La Didacta de lãs Ciencias. Revista Eureka sobre Enseñanza y Divulgación de las Ciencias vol.5 n², p. 134169, 2008.

AULER, D.; DELIZOICOV, Demétrio. Alfabetização Científico-Tecnológica para quê? ENSAIO, Pesquisa em Educação em Ciências, Belo Horizonte, v. 03, n. 02, p. 17-29, 2001.

AULER, D. Alfabetização Científico-Tecnológica: Um novo "paradigma”? ENSAIO, Pesquisa em Educação em Ciências, Belo Horizonte, v. 05, n. 01, p. 69-83, 2003.

BRASIL. Ministério da Educação. Lei de Diretrizes e Bases da Educação Nacional, Brasília, DF, 1996. 
BRASIL. Ministério da Educação, Secretária de Educação Básica. Orientações curriculares para o ensino médio, vol. 2, Brasília, DF, 2006.

BRASIL. Ministério de Minas e Energia, Empresa de Pesquisa Energética. Plano Decenal de Expansão de Energia 2020, Brasília, DF, 2011. Disponível em: < http://www.mme.gov.br/mme/galerias/arquivos/noticias/2011/PDE2020.pdf> Acesso em 29 de maio de 2012.

FONTES, A.; SILVA, I. R. Uma nova forma de aprender ciências. Porto: Asa Editores S.A., 2004.

IRWIN, A. STS Perspectives on scientific governance. In: HACKET. E. J.; AMSTERDAMSKA, O.; LYNCH, M.; WAJCMAN, J. (eds.). The handbook of science and technology studies. Cambridge, MA: MIT Press, p. 583-607, 2008.

KRASILCHIK, M. Ensino de Ciências: Um ponto de partida para a inclusão. In: WERTHEIN, J.; CUNHA, C. (org.) Ensino de Ciências e Desenvolvimento: o que pensam os cientistas, 2 a Ed., Brasília: UNESCO, Instituto Sangari, p. 207-212, 2009.

LÚJAN, J. L. et al. Ciencia, Tecnología y Sociedad: Una Introducción al Estudio Social de la Ciencia y la Tecnología. Madrid: TECNOS, 1996.

PRAIA, J.; GIL-PÉREZ, D.; VILCHES, A. O Papel da Natureza da Ciência na Educação para a Cidadania. Ciência \& Educação, v.13, n. 2, p. 141-156, 2007.

ROTHBERG, D. Por uma agenda de pesquisa em democracia eletrônica. Opinião Pública, v. 14, n. 1, p.149-172, 2008.

ROTHBERG, D. Contribuições a uma teoria da democracia digital como suporte à formulação de políticas públicas. CTS. Ciencia, Tecnología y Sociedad, v. 5, n. 14. p. 1-19, 2010.

SANTOS, W. L. P. Educação científica na perspectiva de letramento como prática social: funções, princípios e desafios. Revista Brasileira de Educação, v. 12, p. 474-492, 2007. 
SANTOS, W. L. P.; MORTIMER, E. F. Uma análise de Pressupostos Teóricos da Abordagem C-T-S (Ciência - Tecnologia - Sociedade) no Contexto da Educação Brasileira. ENSAIO, Pesquisa em Educação em Ciências, Belo Horizonte, v. 02, n. 02, p. 133-162, 2000. SÃO PAULO (Estado); Secretaria da Educação - SEE; Caderno do Aluno; Física; Ensino Médio; 3 a Série, v.2, 2010a.

SÃO PAULO (Estado). Secretaria da Educação - SEE. Caderno do Professor, Física, Ensino Médio, $3^{\text {a }}$ Série, v.2, 2010b.

SÃO PAULO (Estado). Secretária da Educação - SEE. Currículo do Estado de São Paulo: Ciências da Natureza e suas tecnologias, 2010c.

SOUZA, C. A.; BASTOS, F. P.; ANGOTTI, J. A. P. Cultura científico-tecnológica na educação básica. Ensaio, Pesquisa em Educação em Ciências, Belo Horizonte, v. 09, n. 01, p. 62 - 71, 2007.

TEDESCO, J. C. Formação científica para todos. In: WERTHEIN, J., CUNHA, C. (org.) Ensino de Ciências e Desenvolvimento: o que pensam os cientistas, $2^{\mathrm{a}}$ Ed., Brasília: UNESCO, Instituto Sangari, p. 161-172, 2009. 